\title{
Perceptions of Social Media Impact on Social Behavior of Students: A Comparison between Arts and Science Faculty
}

\author{
K. Hashim, King Abdulaziz University, Saudi Arabia \\ L. Al-Sharqi, King Abdulaziz University, Saudi Arabia \\ I. Kutbi, King Abdulaziz University, Saudi Arabia
}

\begin{abstract}
Social media is now a pervasive element impacting the social and cultural fabric of our society. It has revolutionized the way we communicate, interact and socialize. This study investigates differences and similarities of King Abdulaziz University (KAU) Arts and Science instructors' perceptions of social media impact on social behavior of students. Data were collected using a specially designed survey during the academic year 2013/2014. The sample size was 507 instructors of different ages and genders representing Arts and Science colleges. Research outcome indicates that instructors are familiar with and are immersed in social media use. Findings support the advantages of social media use on students' social behavior and do not indicate any obvious disadvantages. Survey results also highlight affinities for various social media tools and purposes of use between the two groups. The findings include identification of college discipline-based dominant views pertaining to advantages and disadvantages of social media on social behavior of students. These findings can help in providing solutions to mitigate concerns relating to the use of social media.
\end{abstract}

Keywords: Social media, social behavior, instructor perception, perception differences, higher education, social media tools 


\section{Introduction}

Social media is now a pervasive element impacting the social fabric of our society and changing the nature of social relationships. It has revolutionized the way we communicate, interact and socialize. New technologies help facilitate and provide flexibility in communicating and sharing of resources. This new approach to consuming and creating information is in particular attractive to youths as a platform and space for activities not possible in the face-to-face context (Lee, Chen, Li \& Lin, 2015). However, excessive use of social media tools by college students has led to debate over whether or not it has changed the very shape and structure of students' social behavior and academic practices, and has thus caused leading educators to redefine their understanding of interpersonal communication and study dynamics (Junco, Merson \& Salter, 2010). As such, it is pertinent to seek the views of faculty pertaining to perceptions of social media impact on social behavior of students.

Students use social media tools for many purposes such as access to information, group discussion, resource sharing and entertainment (Wang, Chen \& Liang, 2011). This has generated speculation on their use and related positive and negative implications, in both the short and long terms. As several studies demonstrate, social media interaction could have positive and negative effects on students. They can provide flexibility in learning, stimulate innovative ideas, and increase interpersonal relationships among students and instructors. These tools, however, can have negative impacts on students as they might distract their attention from the learning process, reduce their physical social interaction and make them potentially addictive.

Studies (Furnham, Batey, Booth, Patela \& Lozinskaya, 2011; Hartley \& Greggs, 1997; Williamson, 2011; Wong\&Cheung, 2011;Zare, 2011)have indicated that there are differences in preferences and abilities of Arts and Science students pertaining to matters such as learning and thinking styles. Likewise, instructors from the two disciplines are assumed to have similar characteristics. As such, this study investigates on the differences and similarities of usage, preferences and perceptions of social media between the two disciplines.

The study explores the research question on whether there are differences in perceptions of social media impact on students' social behavior between Arts and Science instructors. Although many studies have investigated the impact of social media on college students' 
social behavior, few have focused on Saudi Arabia. Hence, this study should contribute valuable findings. Its purpose is to explore the impact of social media on students' social behavior. A research questionnaire was designed to determine the factors that may affect students. Through analysis of the data, the study attempts to detect the positive and negative impacts and identify key themes, trends or perceptions that can be used as a foundation for more in-depth research.

The main contribution of the study lies in identifying discipline-based differences and similarities on instructors' usage, preferences of social media and perceptions of social media on social behavior of students, which can help in discerning positive and negative factors. Given the present limitation of available data on instructors' preferences and perceptions, the data gathered provide valuable source of information, as they offer a deeper insight into the academic community's association with the new media.

\section{Literature Review}

A study (Furnham et al, 2011) revisits the 50 year old "two cultures" debate about differences in thinking styles of Arts and Science students where the central question was whether Arts and Science students differ in their levels of creativity. The outcome of study indicates that Arts students have a divergent style and science students a convergent style. Most creativity is associated with divergent/imaginative thinking whilst in the sciences it remains more convergent thinking. This indicates that universities need to look into learning and thinking styles of the academic communities of various disciplines to allow them to interact, teach and learn effectively.

A study exploring the perceptions of university instructors members for using social media in formal and informal learning (Chen \& Bryer, 2012) indicates that most of the studied population used Facebook for personal communication and LinkedIn for professional purposes. A study by Velenzuela, Park and Kee (2008) supports the notion that both the medium technological capabilities as well as the actual content it transmits influence people's attitudes and behaviors. In this study, two major general observations were made: a) online social networks are effective structures for connecting people, allowing them to create content and participate in public affairs in a meaningful way; and b)social networks are not just a place to spend time in but are useful tools for collective action. 
In a survey done by Bagget and Williams (2012), students agree that social media is a means to connect between individuals and is used as a way to sharing interest. These are useful tools for communication and education, and are a means to keep in touch with people professionally. They provide an opportunity for networking in any profession. With time constraints and demanding class schedules, social media provide an opportunity to multitask because students do not want to spend time creating multiple individual messages. They commonly use Facebook, watch television or a video, talk, email friends and family, and write papers or conduct research all at the same time.

In a study exploring how students use social media, Wang, Chen and Liang (2011) report that most college students spent vast number of hours accessing social media sites. Ninety percent of students surveyed spent their time on entertainment. While eighty percent of the sample admitted that they posted or responded while completing homework, not too many college students preferred using social media to do their homework. Considering the overall results of collected data analysis, there was a negative attitude towards social media when college students used them. The analysis also indicates that an approach is needed to better balance the relationship between social media and academic study.

The frequent use of Facebook could cause addiction toward the site and influence students' daily life at large. A study by Zainudin, Omar, Bolong and Osman (2011) was conducted to identify the relationship between female students' motives for Facebook use and Facebook addiction. Five motives established were social interaction, passing time, entertainment, companionship and communication. The findings of the study showed that there are significant relationship between female students' motives for Facebook use and Facebook addiction. The research concluded that the five motives established were among the major contributor to the addiction of Facebook site.

Madge, Meek, Wellens and Hooley (2009) report on a study conducted with first year undergraduates at a British university using an online survey. Students reported that they specifically joined Facebook pre-registration as a means of making new friends at university, as well as keeping in touch with friends and family at home. The survey data also reveal that once at university, Facebook was a social element that helped students settle into university 
life. Students thought Facebook was used most importantly for social reasons, not for formal teaching purposes.

Liu (2010) studied students' use, attitudes and perceptions of 16 different social media tools through an online questionnaire involving 221 students. The top four reasons that prompted students' use of social media tools were found to be social engagement (85\%), direction communications (56\%), speed of feedback/results (48\%), and relationship building (47\%); less than $10 \%$ used social media tools for academic purposes.

\section{Research Methodology}

This study used both primary and secondary sources. The primary data were collected through a questionnaire administered to randomly selected respondents representing a sample of university instructors from various academic disciplines of KAU. The research team designed and fine-tuned the survey instrument and conducted a workshop to obtain the opinion of administrators, instructors and students on which topics to include.

The survey included a total of 507 instructors who were randomly selected from various colleges of KAU. The target instructors represented a homogeneous mix (male/female), different age groups and disciplines to sufficiently preserve optimal diversity within the collected data required for subsequent analysis.

The questionnaire was pre-tested and revised by several senior university instructors, who, specializing in sampling and questionnaire design, made modifications to enhance clarity. The questionnaire was then pilot tested, using a version that contained the questions in both English and Arabic languages, to provide a survey questionnaire in dual languages for ease of understanding. Based on the target numbers, copies of the questionnaire were then distributed to instructors.

The questionnaire was divided into four parts. In the first part, instructors were requested to respond to general and demographic questions about their gender, age, and field of specialization. Instructors were also asked about their level of association with the Internet and social media use. The second part provided more specific questions on the types of social media instructors use and the purpose for which they use social media. The third part 
addressed on questions related to instructors' perspectives on the benefits of social media on social behavior of students. While the fourth part focused on their views on the negative aspects. Completed responses were collated and submitted to coordinators. A statistician was engaged to ensure that processing of data was done properly. Data were coded and processed into SPSS, a statistical package system. Results were analyzed and summarized, in order to draw conclusions and make recommendations.

The raw data from the returned questionnaires were then coded and entered into the statistical system. The data were explored both for their descriptive statistics (i.e. calculation of percentage distributions, frequency distributions, calculations of averages, and coefficient of variation) and inferential statistics (i.e. level of significance, t-test, z-test, ANOVA, correlation and regression and classification analysis). Cronbach's Alpha was also used to provide indications of internal consistency.

\section{Results and Discussion}

A total of 507 instructors participated in the survey pertaining to impact of social media on social behavior of students. The total sample size meant an acceptable error of $\pm 4 \%$ at 95 percent confidence level for the university population. The demographic breakdown on gender, age group and academic rank is given in Table 1. In terms of gender, the sample population comprised 61 percent male and 39 percent female instructors. The dominant age group is the ' 30 to less than 40 years' category while the dominant academic rank is the 'assistant professor' category. The sampled gender and age cohorts provide a consistent representative sample of the ratios of the overall KAU instructor population.

Table 1.Demographic breakdown on gender, age group and academic rank

\begin{tabular}{|c|c|c|c|c|c|c|c|}
\hline & & & Science & & Arts & & tal \\
\hline & & Cour & $\begin{array}{l}\text { Row Column } \\
N \% N \%\end{array}$ & Coun & $\begin{array}{l}\text { Row Column } \\
N \% N \%\end{array}$ & Count & \\
\hline Gender & Male & 241 & $78.0 \quad 63.3$ & 68 & $22.0 \quad 54.0$ & 309 & 60.9 \\
\hline & Female & 140 & 70.736 .7 & 58 & $\begin{array}{ll}29.3 & 46.0\end{array}$ & 198 & 39.1 \\
\hline & Total & 381 & $\begin{array}{ll}75.1 & 100.0\end{array}$ & 126 & 24.9100 .0 & 507 & 100.0 \\
\hline Age & less than 30 & 44 & $\begin{array}{ll}69.8 & 11.5\end{array}$ & 19 & $\begin{array}{ll}30.2 & 15.1\end{array}$ & 63 & 12.4 \\
\hline
\end{tabular}




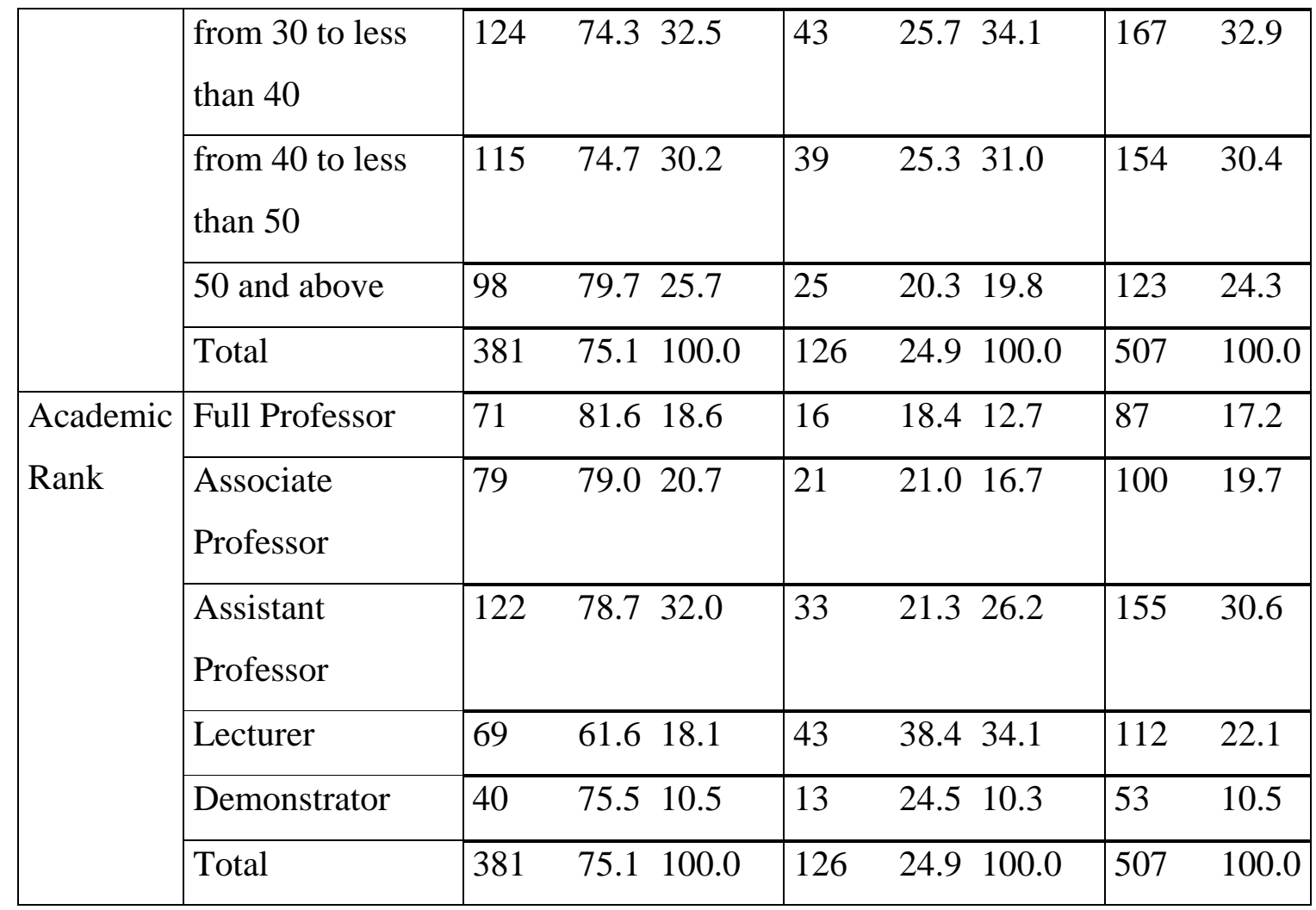

In investigating significant difference, the Pearson Chi-square test of independence is used. If chi-square results are significant, post-hoc analysis is then conducted for identifying significant differences at the 0.05 level through column proportions z-tests approach (adjust p-values for multiple comparisons Bonferroni method).

\section{Instructors' Background on the Internet and Social Media}

The survey included some questions designed to provide information about KAU instructors' background in using the Internet and social media. These questions are shown in Table 2, together with their corresponding responses. The responses indicated that KAU instructors are familiar with and are immersed in the Internet and social media use. 
Table 2.KAU instructors' background in Internet and social media

\begin{tabular}{|c|c|c|c|c|c|}
\hline & \multicolumn{4}{|c|}{ College Type } \\
\hline & & \multicolumn{2}{|c|}{ Science } & \multicolumn{2}{|c|}{ Arts } \\
\hline & & Count & $\%$ & Count & $\%$ \\
\hline \multirow{4}{*}{$\begin{array}{l}\text { On average how many hours do you } \\
\text { spend using internet per week? }\end{array}$} & less than 5 & 33 & 8.7 & 14 & 11.1 \\
\hline & $\begin{array}{l}\text { from } 5 \text { to less than } \\
10\end{array}$ & 97 & 25.5 & 30 & 23.8 \\
\hline & $\begin{array}{l}\text { from } 10 \text { to less } \\
\text { than } 15\end{array}$ & 91 & 23.9 & 32 & 25.4 \\
\hline & 15 hours or more & 160 & 42.0 & 50 & 39.7 \\
\hline \multirow{2}{*}{$\begin{array}{l}\text { Do you currently have a personal } \\
\text { social media account? }\end{array}$} & Yes & 352 & 92.4 & 105 & 83.3 \\
\hline & No & 29 & 7.6 & 21 & 16.7 \\
\hline \multirow{5}{*}{$\begin{array}{l}\text { On average how many hours do you } \\
\text { spend using social media per week? }\end{array}$} & none & 29 & 7.6 & 21 & 16.7 \\
\hline & less than 3 & 102 & 26.8 & 31 & 24.6 \\
\hline & $\begin{array}{l}\text { from } 3 \text { to less than } \\
6\end{array}$ & 93 & 24.4 & 25 & 19.8 \\
\hline & $\begin{array}{l}\text { from } 6 \text { to less than } \\
10\end{array}$ & 84 & 22.0 & 28 & 22.2 \\
\hline & 10 hours or more & 73 & 19.2 & 21 & 16.7 \\
\hline \multirow[t]{4}{*}{ Using social media for? } & none & 29 & 7.6 & 21 & 16.7 \\
\hline & less than 1 year & 25 & 6.6 & 9 & 7.1 \\
\hline & $1-3$ years & 135 & 35.4 & 31 & 24.6 \\
\hline & more than 3 years & 192 & 50.4 & 65 & 51.6 \\
\hline \multirow{4}{*}{$\begin{array}{l}\text { Which language do you prefer when } \\
\text { you visit social media? }\end{array}$} & English & 82 & 21.7 & 35 & 28.0 \\
\hline & Arabic & 102 & 27.0 & 20 & 16.0 \\
\hline & Both & 191 & 50.5 & 69 & 55.2 \\
\hline & Others & 3 & 0.8 & 1 & 0.8 \\
\hline
\end{tabular}

The majority of instructors from the Science and Arts colleges are using the Internet for 10 hours or more per week. The major category for Science and Arts groups is the ' 15 hours or more' category. The value of the Pearson Chi-Square has $p$ greater than 0.01. Hence, the responses are not significantly different. 
More than $80 \%$ of instructors from the Science and Arts colleges have a personal social media account with the Science group having a higher percentage. The value of the Pearson Chi-Square is significant at $\mathrm{p}$ less than 0.01. Hence, the responses have strong significant difference. Post-hoc analysis indicates that significant difference exist under the 'Yes' category with Science instructors having a greater proportion of responses than the Arts instructors and this difference is significant at 0.05 level. Likewise, under the 'No' category, the proportion of Arts instructors is more than the Science instructors. This indicates that the Science instructors are dominant in having a personal social media account. On the average number of hours instructors spend using social media per week, the major category for the Science and Arts groups is the 'less than 3 hours' category. The value of the Pearson ChiSquare has $p$ greater than 0.01 . Hence, the responses are not significantly different.

More than 50 percent of instructors from both the college groups have been using social media tools for more than 3 years. The value of the Pearson Chi-Square is significant at $\mathrm{p}$ less than 0.01.Hence, the responses have strong significant difference. Post-hoc analysis indicates that the proportion of Science instructors under the category '1-3 years' is greater than the proportion of Arts instructors. Likewise, the proportion of Arts instructors under the 'None' category is greater than the Science instructors. This indicates that Science instructors are more matured than Arts instructors in terms of duration of social media usage. These findings reflect the maturity of KAU instructors regarding use of the Internet and social media.

On the preferred language when visiting or using social media, the majority of instructors from both college groups selected category 'Both' (English and Arabic languages). This indicates that instructors of both college groups are mostly bilingual in their use of social media. The value of the Pearson Chi-Square has $\mathrm{p}$ greater than 0.01 .Hence, the responses are not significantly different.

\section{Instructors' Preferred Social Media Tools}

We sought to answer the questions related to social media tools most commonly used by instructors. Figure 1 shows the distribution of social media tools per type of college. The survey question was of multiple response type. From the figure we note that the density of KAU instructors' usage of social media differs much. 
Amongst the 2 groups, the top two categories are 'Facebook' and 'YouTube'. The finding pertaining to Facebook is in line with the finding of a study done by Chen and Bryer (2012) in which Facebook was identified as one of the most popular social media tools used by instructors. For the Science group, category 'Facebook' is topmost while for the Arts group category 'YouTube' is topmost. For the third position category, the Science group is represented by Twitter while for the Arts group it is Wikipedia. Wikipedia has higher preference level compared to Twitter for the Arts instructors group, unlike the Science group. As Wikipedia is an encyclopedic facility related to learning, this signifies that Arts instructors have stronger inclination towards using social media for learning.

The value of the Pearson Chi-Square is significant at $\mathrm{p}$ less than 0.05 suggesting that there exists an association between the social media tools and the college groups. Post-hoc analysis indicates categories 'Blogger' and 'Slideshare' have greater proportions of responses by the Arts instructors and that these differences are significant at the 0.05 level. This indicates that Arts instructors are using more of these tools than the Science instructors. 


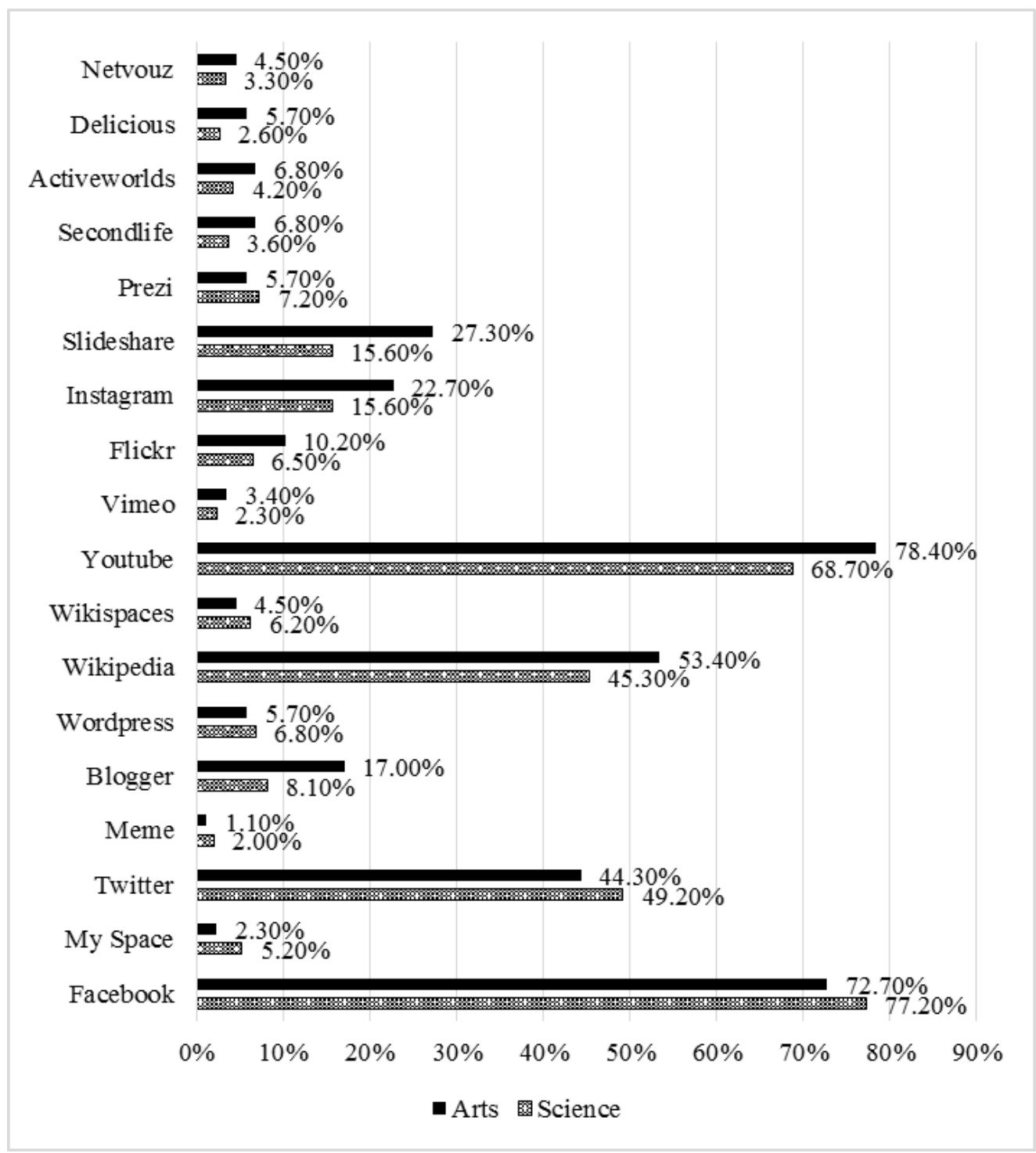

Figure 1. College type breakdown in social media tool usage

\section{Purposes on Usage of Social Media}

Figure 2 shows the discipline breakdown for purposes of social media tool usage. It shows the distribution of instructors sample as per the most common purposes. The survey question was of multiple response type. The figure reveals that KAU instructors use social media tools for a blend of academic and non-academic purposes.

Amongst the two college groups, the top 3 categories are 'Searching for information', 'Learning and 'Exchange ideas'. For the Science group, category 'Searching for information' is topmost followed by category 'Learning' and then category 'Exchange ideas' while for the Arts group, category 'Learning' is topmost followed by category 'Searching for information' 
and then category 'Exchange ideas'. The categories' Searching for information' and 'Exchange ideas' are identified with knowledge building and the domain of learning.

A point to note is that 48.4 percent of the Science instructors selected category 'Teaching' while 47.1 percent of the Arts instructors selected the same. It is also worthwhile to note that the responses for categories 'Searching for information' and 'Learning' are both above 60 percent for both groups. This indicates a moderately high percentage of instructors use social media for learning. The value of the Pearson Chi-Square has p greater than 0.01. This means that there are no significant differences among the responses across the Science and Arts groups for purposes of social media tool usage.

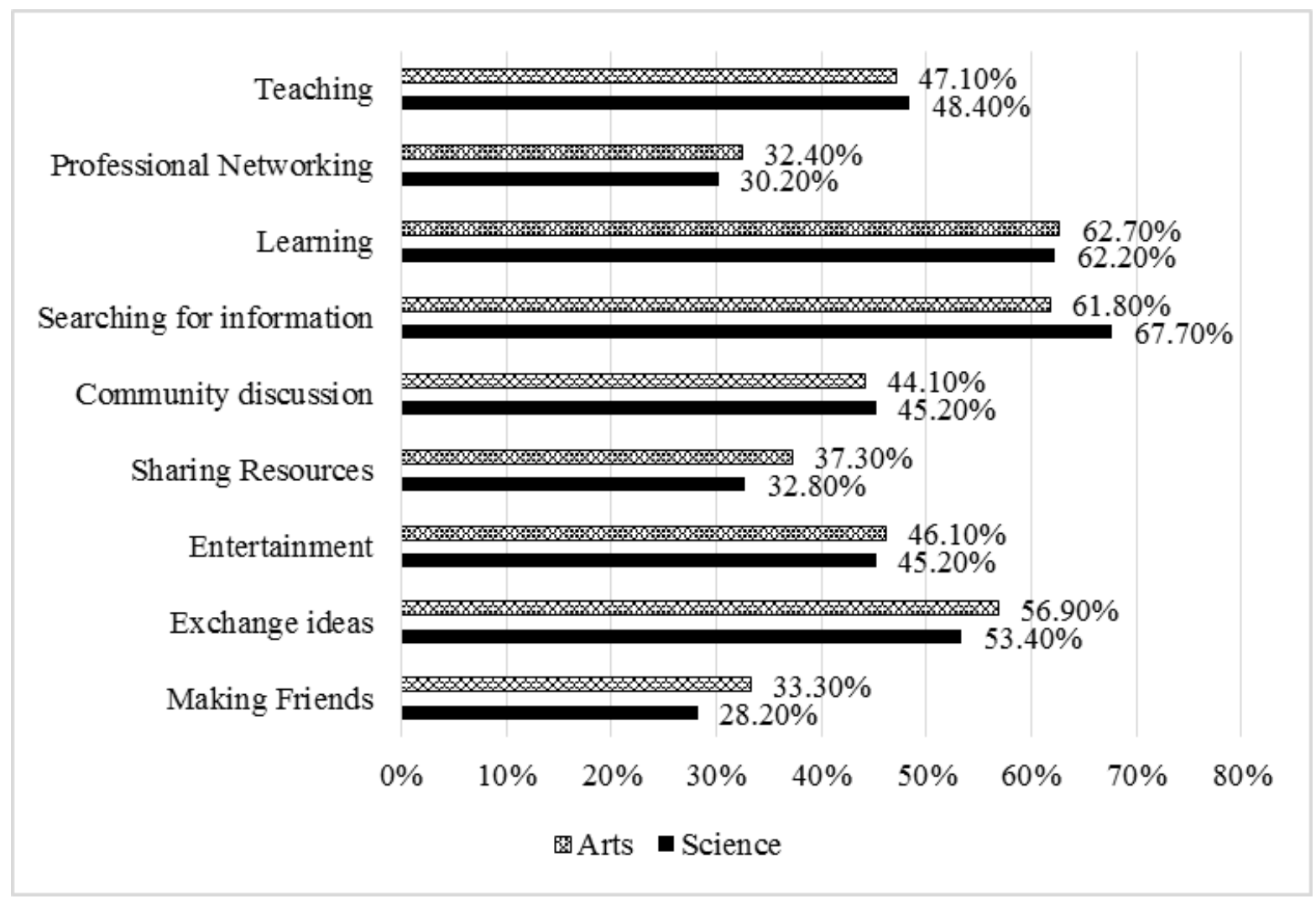

Figure 2. Distribution for purposes of social media tool usage under college type

\section{Evaluating Instructors' Perceptions of Social Media Usage on Social Behavior of}

\section{Students}

The remaining portion of the questionnaire was designed to investigate KAU instructors' perceptions regarding the following: a) rating a set of 9 statements as benefits (advantages) of students' social media usage on their social behavior; and b) rating a set of 7 statements as 
problems (disadvantages) of social media usage on social behavior. Data regarding perceptions on the advantages and disadvantages were collected using a five-point Likert level of agreement scale. The variation in opinions is low based on the coefficient of variation for all statements. This indicates that instructors are aware of the advantages and disadvantages of using social media on social behavior.

Table 3 shows the overall rating of responses on the two factors, advantages and disadvantages. Based on Table 4 which provides the mean and corresponding agreement attitude, the mean values for factor advantages of both groups are of attitude 'Agree' while the mean values for factor disadvantages for both groups are of attitude 'Unsure'. This indicates that both groups agree with the advantages but are unsure of the disadvantages.

Table 3. Mean distribution over factors for advantages and disadvantages

\begin{tabular}{|lcc|}
\hline & Science & Arts \\
& Mean & Mean \\
\hline Advantages of social media usage on social behavior & 3.86 & 3.88 \\
\hline Disadvantages of social media usage on social behavior & 2.96 & 2.93 \\
\hline
\end{tabular}

Table 4. Mean and corresponding agreement attitude

\begin{tabular}{|l|l|}
\hline \multicolumn{1}{|c|}{$\begin{array}{c}\text { Value of weighted } \\
\text { mean }\end{array}$} & Agreement attitude \\
\hline From 1 to 1.79 & Strongly Disagree \\
\hline From 1.80 to 2.59 & Disagree \\
\hline From 2.60 to 3.39 & Unsure \\
\hline From 3.40 to 4.19 & Agree \\
\hline From 4.20 to $\%$ & Strongly Agree \\
\hline
\end{tabular}

Cronbach's alpha $(\alpha)$ was used to test for reliability of results. The study factors are reliable as shown in Table 5 by Cronbach's alpha values of greater than 82 percent. 
Table 5. Cronbach's alpha for the study factors on instructors

\begin{tabular}{|l|c|c|c|}
\hline Study factor & No. of items & Science $(\alpha)$ & Arts $(\alpha)$ \\
\hline $\begin{array}{l}\text { Advantages of social media usage on social } \\
\text { behavior }\end{array}$ & 9 & 0.853 & 0.854 \\
\hline $\begin{array}{l}\text { Disadvantages of social media usage on social } \\
\text { behavior }\end{array}$ & 7 & 0.867 & 0.824 \\
\hline
\end{tabular}

\section{Investigation of Dominant Issues Pertaining To Advantages of Social Media Usage on Social Behavior}

Out of the items under each factor, we selected the top fivesub-factors on advantages by mean values from survey responses of both groups and combined them into a comparison list. This helps identify support factors of social media usage on social behavior of students. The summary for sub-factors on advantages is given in Table 6 .

Table 6. Summary table for combined top five sub-factors for advantages of social media usage on social behavior

\begin{tabular}{|c|c|c|c|c|}
\hline & \multicolumn{2}{|c|}{ Science } & \multicolumn{2}{|c|}{ Arts } \\
\hline Factor & Mean & $\begin{array}{c}\text { Position } \\
\text { Within } \\
\text { Top } 5\end{array}$ & Mean & $\begin{array}{c}\text { Position } \\
\text { Within } \\
\text { Top } 5\end{array}$ \\
\hline $\begin{array}{l}\text { Students share ideas and knowledge with a } \\
\text { wider and more varied audience }\end{array}$ & 4.01 & 1 & 4.17 & 1 \\
\hline $\begin{array}{l}\text { Students collaborate with other students in } \\
\text { achieving the goal of a project }\end{array}$ & 3.97 & 2 & 3.98 & 2 \\
\hline $\begin{array}{l}\text { Students participate in group decision } \\
\text { making }\end{array}$ & 3.81 & & 3.86 & 5 \\
\hline $\begin{array}{l}\text { Improve students' connectedness to } \\
\text { communities }\end{array}$ & 3.89 & 4 & 3.90 & 3 \\
\hline $\begin{array}{l}\text { Students understand community issues in a } \\
\text { better way }\end{array}$ & 3.89 & 4 & 3.90 & 3 \\
\hline $\begin{array}{l}\text { Improve students ability to contribute to } \\
\text { society }\end{array}$ & 3.95 & 3 & 3.84 & \\
\hline
\end{tabular}


The above table highlights the combined top five views of the two college groups with mean values pertaining to advantages of social media usage on social behavior of students. The table highlights four common factors below in decreasing priority (order of means):

- Students share ideas and knowledge with a wider and more varied audience

- Students collaborate with other students in achieving the goal of a project

- Improve students' connectedness to communities

- Students understand community issues in a better way

It is worth noting that two uncommon factors in the combined top five list of both groups are the factor 'Improve students ability to contribute to society' of the Science group and the factor 'Students participate in group decision making' of the Arts group. Here we can see the difference in emphasis and priority of the two groups with the Science group having interest in students' contribution to society while the Arts group emphasizes on participation in group decision making. The Arts group has dominant perceptions (higher means) over the Science group relating to the advantages on all the common factors discussed except for the factor pertaining to improving students' ability to contribute to society.

\section{Investigation of Dominant Issues Pertaining To Disadvantages of Social Media Usage on}

\section{Social Behavior}

Out of the items under each factor, we selected the top five sub-factors on disadvantages by mean values from survey responses of both college groups and combined them into a comparison list. This helps highlight potential problems of social media usage on social behavior of students. The summary for sub-factors on disadvantages is given in Table 7 .

Table 7. Summary table for combined top five sub-factors on disadvantages of social media usage on social behavior

\begin{tabular}{|l|l|l|l|l|}
\hline & \multicolumn{2}{|c|}{ Science } & \multicolumn{2}{c|}{ Arts } \\
\hline Factor & Mean & Position & Mean & Position \\
& & Within & & Within \\
& & Top 5 & & Top 5 \\
\hline Expose students to bullying and domination & 3.03 & 4 & 2.84 & 4 \\
\hline
\end{tabular}




\begin{tabular}{|l|l|l|l|l|}
\hline attitudes & & & & \\
\hline $\begin{array}{l}\text { Cause less productivity and distraction from } \\
\text { everyday life activities }\end{array}$ & 3.17 & 3 & 3.20 & 2 \\
\hline Cause students to become less sociable & 3.21 & 2 & 3.11 & 3 \\
\hline Make students become physically inactive & 3.48 & 1 & 3.63 & 1 \\
\hline Make students become mentally dull & 2.82 & 5 & 2.68 & 5 \\
\hline
\end{tabular}

The above table highlights the combined top five sub-factors of the two college groups with mean values pertaining to disadvantages of social media usage on social behavior of students. The table highlights five common factors below in decreasing priority (order of means):

- Make students become physically inactive

- Cause less productivity and distraction from everyday life activities

- Cause students to become less sociable

- Expose students to bullying and domination attitudes

- Make students become mentally dull

It is worth noting that the top five concerns for both groups are representedby the same factors but with a difference in the order of priority for the second and third positions. For the Science group, the second position is taken by factor 'Cause students to become less sociable' while in the Arts group this factor is in third position. It is interesting to note that the top three concerns relate to physical inactivity, introversion; and unproductivity and distraction. The Science group has dominant perceptions (higher means) over Arts group relating to disadvantages on social behavior on all the common factors discussed except for the factors pertaining to unproductivity and distraction; and physical inactiveness.

\section{Conclusions}

KAU instructors are familiar with and use social media. They use different categories of the social media tools for academic and non-academic purposes. Instructors agree on the advantages of social media usage on social behavior of students but are unsure of the disadvantages. This paper captured the perceptions of each group. Common perception on advantages include ability of students to share ideas and knowledge with a wider and more 
varied audience, collaborate with other students in achieving the goal of a project, improve students' connectedness to communities and understand community issues in a better way. Uncommon factors include the Science group having interest in students' contribution to society while the Arts group emphasizes on participation in group decision making. Common concerns include physical inactivity, unproductivity and distraction, introversion, exposure to bullying and domination attitudes; and mental dullness. These findings can help identify possible strategies to mitigate concerns identified by the instructors. 


\section{References}

Bagget, S.B., \& Williams, M. (2012). Student Behaviors and Opinions Regarding the Use of Social Media, Mobile Technologies, and Library Research, Virginia Libraries, 58(1), 19-22. Retrieved from http://scholar.lib.vt.edu/ejournals/VALib/v58_n1/baggett.html.

Chen, B., \& Bryer, T. (2012). Investigating Instructional Strategies for Using Social Media in Formal and Informal Learning. The International Review of Research in Open and Distance Learning, 13(1), 87-104.

Furnham, A., Batey, M., Booth, T. W., Patela, V., \& Lozinskaya, D. (2011). Individual difference predictors of creativity in Art and Science students. Thinking Skills and Creativity, 6(2), 114-121.

Hartley, J., \& Greggs, M. (1997). Divergent thinking in arts and science students: Contrary Imaginations at Keele revisited. Studies in Higher Education, 22(1), 93-97.

Junco, R., Merson, D., \& Salter, D. W. (2010). The Effect of Gender, Ethnicity, and Income on College Students' Use of Communication Technologies. Cyberpsychology, Behavior and Social Networking, 13(6), 619-627.

Lee, L., Chen, D., Li, J., \& Lin, T. (2015). Understanding new media literacy: The development of a measuring instrument, Computers and Education, 85, 84-93.

Liu, Y. (2010). Social Media Tools as a Learning Resource. Journal of Educational Technology Development and Exchange, 3(1), 101-114.

Madge, C., Meek, J., Wellens, J., \& Hooley, T. (2009). Facebook, social integration and informal learning at university: 'It is more for socialising and talking to friends about work than for actually doing work'. Learning, Media and Technology, 34 (2), 141155.

Mazman, S. G., \& Usluel, Y. K. (2011). Gender Differences in Using Social Networks, Turkish Online Journal of Educational Technology, 10(2), 133-139.

Velenzuela, S., Park, N., \& Kee, K.F. (2008). Lessons from Facebook: The Effect of Social Network Sites on College Students' Social. Retrieved from https://online.journalism.utexas.edu/2008/papers/Valenzuela.pdf.

Wang, Q., Chen, W., \& Liang, Y. (2011). The Effects of Social Media on College Students. Johnson \& Wales University. Retrieved from http://scholarsarchive.jwu.edu/cgi/viewcontent.cgi?article=1004\&context=mba_stude nt. 
Williamson, P. K. (2011). The creative problem solving skills of arts and science studentsThe two cultures debate revisited. Thinking Skills and Creativity, 6(1), 31-43.

Wong, K. C. K., \& Cheung, W. K. W. (2011). A study of ICT literacy in Arts and Science students. Proceedings of 4th International Conference on Interaction Sciences (ICIS), $5-7$.

Zainudin, S.S., Omar, S.Z., Bolong, J., \& Osman, M.N. (2011), Facebook Addiction Among Female University Students, Revista De Administrajie Publicasi Politici Sociale, 2(7). Retrieved from http://revad.uvvg.ro/index.php?option=com_content\&view=article\&id=93:facebookaddiction-among-female-university-students\&catid=42:issue-no-7\&Itemid=63.

Zare, B. (2011). Creativity Differences between Art and Engineering Students. Proceedings of 2011 International Conference on E-business, Management and Economics. 